\title{
TIPOLOGIAS E VULNERABILIDADES DAS PAISAGENS EM BACIAS HIDROGRÁFICAS.
}

\author{
João Cândido André da Silva Neto
}

\section{Natacha Cíntia Regina Aleixo²}

RESUMO: A vulnerabilidade da paisagem pode ser definida pela ausência de condições que sustenta a integridade da estrutura e dinâmica de uma determinada paisagem, resultando em mudanças e transformações representativas no contexto da totalidade. Desse modo, o entendimento da configuração da paisagem ultrapassa a esfera ambiental, sendo condicionada por fatores sociais, que influenciam diretamente nas tipologias das paisagens e seus níveis de vulnerabilidade, pois, conforme Vitte (2007) a paisagem é o resultado imediato da intencionalidade humana na superfície terrestre. Assim, o presente artigo abordou as configurações da paisagem na bacia hidrográfica do Rio Salobra, localizada no Planalto da Bodoquena, região sudoeste do Estado do Mato Grosso do Sul, buscando identificar as diferentes tipologias da paisagem e estabelecer uma relação direta com os níveis de vulnerabilidade influenciada pela intensidade antrópica. Para isso, utilizou-se de revisão bibliográfica pertinente à temática com a discussão do conceito de paisagem e suas distintas tipologias, caracterizada pelos diferentes níveis de alterações humanas na natureza, que segundo Suertegaray (2001) são produzidas a partir de intencionalidades que podem ser visualizadas na materialização das ações humanas sobre a natureza.. Além disso, utilizou-se do registro fotográfico para avaliação das diferentes tipologias de paisagem e das formas de uso e ocupação solo, bem como dos dados de vulnerabilidade a perda de solo na área. Concluiu-se que o estudo da paisagem e o entendimento de sua estrutura e dinâmica possibilitam subsidiar e direcionar as ações humanas para preservação das características naturais importantes para a estabilidade e preservação da Bacia Hidrográfica do Rio Salobra.

Palavras-chave: Tipologias. Vulnerabilidade. Análise da paisagem.

\footnotetext{
${ }^{1}$ Doutor em Geografia pela UNESP Campus de Presidente Prudente, Professor Adjunto da Universidade do Estado do Amazonas.

${ }^{2}$ Doutora em Geografia pela UNESP Campus de Presidente Prudente, Professora Adjunta da Universidade do Estado do Amazonas.
} 


\section{1- INTRODUÇÃO}

A ciência geográfica incorporou a análise da paisagem ao tratamento da natureza sob um ponto de vista das dinâmicas naturais em interação com as relações sociais de produção, entendido aqui como resultado das interações e conexões entre a sociedade na natureza (MENDONÇA, 1998).

A inserção das relações sociais que se desenvolviam e influenciavam diretamente a natureza resultaram em tentativas para se estabelecer novas metodologias, com o objetivo de abordar a paisagem sob um caráter eminentemente geográfico, oriundo da relação binômio: Sociedade e Natureza.

Segundo Moss (2000) os estudos sobre ecologia da paisagem é visto como uma potencial fonte para alguns fundamentos teóricos para questões críticas da gestão de recursos naturais.

Os estudos ligados à paisagem possibilitam o entendimento das relações recíprocas resultantes entre sociedade e natureza, onde cada elemento envolvido nessa inter-relação desempenha um papel significativo no todo, e o todo por sua vez reflete essas influências nas suas variáveis.

Enfatiza-se assim, que na transformação antropogênica das paisagens, é usual distinguir duas tendências quanto à modificação da estrutura paisagística e as mudanças dos parâmetros da diversidade.

A primeira tendência é a homogeneização das paisagens, que é determinada pela imposição de um mesmo tipo e grau de utilização e de estilo tecnológico em diferentes paisagens.

Essa tendência conduz a simplificação da estrutura paisagística e a redução da diversidade da paisagem. Esta tendência é caracterizada nos grandes cultivos (monoculturas) e nos processos de "modernização tecnológica" no uso dos recursos naturais, um exemplo no caso da presente pesquisa seria a mecanização agrícola (MATEO et al. 2007). 


\section{Then

A segunda tendência é a heterogeneização das paisagens, determinada pela imposição de diferentes tipos e graus de utilização e de estilos tecnológicos em um mesmo tipo de paisagem. Ela conduz uma maior complexidade da estrutura paisagística e o incremento da diversidade (MATEO et al. 2007).

Para os autores citados essas paisagens podem ser definidas como "formação antropo-natural", consistindo num sistema territorial composto por elementos naturais e antropotecnogênicos condicionados socialmente, que modificam ou transformam as propriedades das paisagens naturais originais.

Nessa perspectiva, o presente artigo discutiu os conceitos de vulnerabilidade e tipologias da paisagem, no qual foram apresentados exemplos para tipologia de paisagem e seus distintos níveis de vulnerabilidade.

\section{2 - DESENVOLVIMENTO}

\section{1 - VULNERABILIDADE DAS PAISAGENS}

Entende-se por vulnerabilidade das paisagens a conjuntura que uma determinada área possa estar sujeita e, que atrelada à falta de condições específicas para manter- se estável, pode alterar as qualidades iniciais dos atributos da paisagem.

Vulnerabilidade pode ser definida ainda pela ausência de condições que sustentam a integridade da estrutura e dinâmica de uma determinada paisagem, resultando em mudanças e transformações representativas no contexto da totalidade. Vulnerabilidade pode significar estar suscetível à transformação de um estado inicial a um estado atual transfigurado pela ação antrópica.

Assim, a ausência das condições estaria associada ao número expressivo de variáveis, que implicaria em abordá-las de acordo com os interesses das situações. 
Tagliani (2003) considerou que a vulnerabilidade ambiental significa a maior ou menor suscetibilidade de um ambiente a um impacto potencial provocado por um uso antrópico qualquer, avaliada segundo vários critérios ou variáveis.

Andersen e Gosk (1987 apud Melo, 2011) definiram vulnerabilidade ambiental como qualquer conjunto de fatores ambientais de mesma natureza que, na presença de atividades atuais ou futuras, poderão sofrer adversidades e comprometer, de forma completa ou parcial, o equilíbrio ecológico da região em análise.

Nápoles (2008) traz uma definição interessante para vulnerabilidade ao tratá-la sob uma perspectiva social, abordando outros dois conceitos, robustez e resiliência.

O primeiro significa que as propriedades estruturais e outras de um sistema the permitem tratar dos distúrbios, sem que os mesmo provoquem mudanças duráveis em sua estrutura e dinâmica.

O segundo conceito seria a capacidade de um sistema absorver e utilizar, ou ainda beneficiar-se das perturbações e mudanças que o arranjam de tal modo, que não provocam mudanças qualitativas na estrutura do sistema.

Assim, Nápoles (2008) considerou:

\begin{abstract}
"Para comprender el significado de la vulnerabilidad se precisa de esos dos conceptos, la diferencia entre éstos, por lo tanto, parece encontrarse en el sentido que los cambios (no estructurales) en las dinámicas pueden ser introducidos en un sistema bajo el impacto de cambios en las circunstancias externas. La "vulnerabilidad" se refiere a la instancia donde ni la robustez ni la resiliência permiten a un sistema sobrevivir sin cambios estructurales. En tales casos, o bien el sistema se adapta estructuralmente o se dirige al caos." (NÁPOLES ${ }^{3}, 2008$, p.142).
\end{abstract}

Desse modo, a vulnerabilidade indica dois caminhos distintos para um determinado sistema: a adaptação da sua estrutura conforme as mudanças estabelecidas, ou o direcionamento para a degradação do sistema.

\footnotetext{
${ }^{3}$ Tradução nossa: "Para compreender o significado de vulnerabilidade necessita-se destes dois conceitos, a diferença entre eles, portanto, parece ser no sentido de que as mudanças (não estruturais) na dinâmica podem ser introduzidas em um sistema sob o impacto de mudanças nas circunstâncias externas. A "vulnerabilidade" refere-se à instância onde nem a robustez nem a capacidade de resistência permitem a um sistema sobreviver sem mudanças estruturais. Em tais casos, ou bem, o sistema adapta-se estruturalmente, ou dirige-se para o caos."
} 


\section{Then

Estabelecer o que diz respeito à vulnerabilidade, permite considerar que cada variável contribui de alguma maneira para o grau de vulnerabilidade, por exemplo, a vulnerabilidade das paisagens à perda de solos, proposta por Crepani (2008) para identificar por meio de variáveis da paisagem, os graus de vulnerabilidade à perda dos solos, na qual são abordadas variáveis que estão diretamente ligadas aos processos de perda de solos, atribuindo assim valores para cada variável, de acordo com suas vulnerabilidades.

Crepani (2008) considerou que os tipos de atividade antrópica desenvolvida sobre uma determinada unidade de paisagem podem representar sua destruição devido a sua pequena capacidade de absorver os estímulos advindos da atividade econômica. Assim considera-se que a vulnerabilidade das paisagens, além dos condicionantes naturais, como tipos de solos, relevo, clima, geologia, é fortemente influenciada pela atuação antrópica.

Nesses termos, é necessário diferenciar a vulnerabilidade da paisagem em duas tipologias distintas, a primeira seria a vulnerabilidade natural, definida como a ausência natural de qualidades que uma paisagem teria para sustentar sua estrutura e dinâmica, resultando na adaptação a uma nova estrutura e dinâmica, ou na degradação da paisagem.

Um bom exemplo para esse caso seria nas paisagens que apresentam relevo fortemente dissecado, solos suscetíveis à erosão, rochas pouco resistentes e forte intensidade pluviométrica na área.

A segunda tipologia seria a influencia do fator antrópico, definida como a paisagem que torna-se vulnerável de acordo com a intensificação da atuação antrópica em áreas que apresentam alguma sensibilidade para que sua dinâmica e estrutura sejam alteradas. Por exemplo, as áreas de desmatamento que alteram as dinâmicas de escoamento superficial, intensificando os processos erosivos, levando à perda significativa de solos. 
Assim, considera-se que a vulnerabilidade das paisagens à perda solos, além dos condicionantes naturais, como tipos de solos, relevo, clima, geologia, é fortemente influenciada pela atuação antrópica.

\section{2 - AS TIPOLOGIAS DAS PAISAGENS.}

As relações entre sociedade e natureza implicam nas mais diversas configurações das paisagens e, suas formas refletem as intencionalidades de quem as impõe somadas com as heranças do passado e presente (Figura 2).

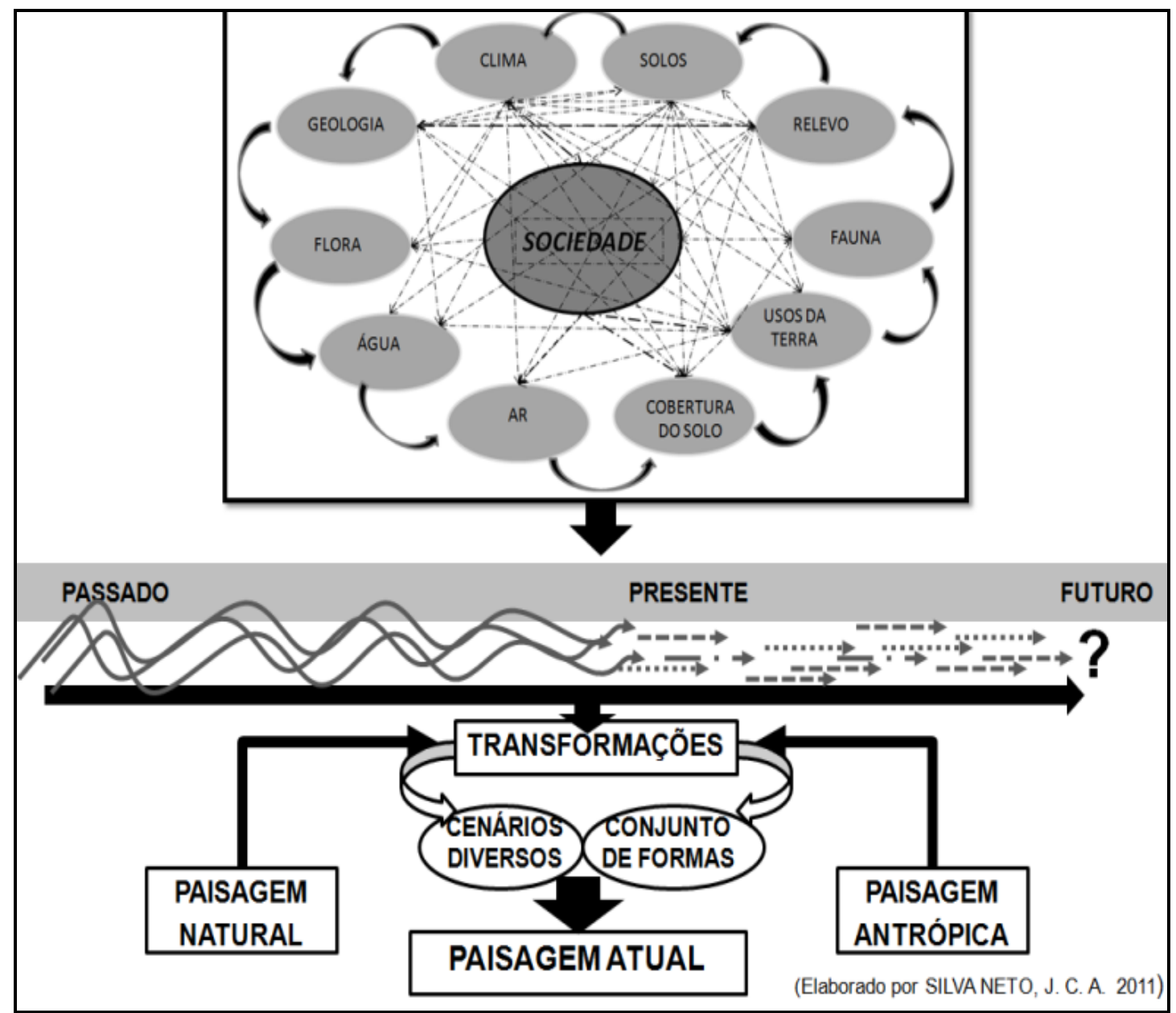

Figura 2: Organograma das relações que resultam na paisagem. 
O organograma (figura 2) representa as relações e conexões que se estabelecem (presente) ou se estabeleceram (passado), entre os elementos da natureza e a sociedade, que resultaram em cenários diversos e conjuntos de formas definindo assim uma paisagem atual que exprime essas relações resultantes das paisagens naturais e das paisagens antrópicas.

O organograma representa que as transformações ao longo do tempo, ocorrem de maneiras distintas, o passado é representado por uma seta assimétrica, indicando a referência ao tempo longo da natureza, também definido como tempo da morfogênese, ou segundo Suertegaray e Nunes (2001) o tempo que escoa.

O presente é representado, por várias setas retas e pontilhadas, indicando a rapidez e as diversas dinâmicas oriundas da atuação direta do homem na natureza, essa relação é capaz de gerar várias transformações na paisagem em períodos curtos.

Quanto ao futuro, apenas se pode considerar as incertezas, probabilidades e possibilidade, ou seja, não é possível prever qualquer cenário para futuro, mesmo se considerando um futuro próximo.

Para se entender a paisagem é necessário compreender sua dinâmica do passado, onde as transformações da paisagem natural foram impulsionadas principalmente por suas próprias forças naturais.

A paisagem natural desse modo, expressa uma conjuntura das dinâmicas estabelecidas pelas inter-relações e conexões num tempo diferente do atual em que as relações da natureza ocorrem de maneira menos intensa, quando comparada com as paisagens atuais.

As paisagens atuais resultam de dinâmicas em que a relação entre sociedade e natureza ocorre de modo mais intenso, seguindo outro ritmo, não mais o tempo que escoa ou tempo da morfogênese.

O presente é caracterizado por paisagens oriundas do tempo curto, tempo da morfodinâmica ou do "tempo que se faz" definido como: natureza a dimensão antropogênica, não levada em conta quando nos detemos a 
refletir na ótica do tempo que escoa. (...) O tempo que faz é percebido como um período curto, incapaz de gerar transformações da ordem daquelas analisadas quando se trabalha com a concepção de tempo profundo". (SUERTEGARAY e NUNES, 2001).

Suertegaray e Nunes (2001) ressaltam ainda, que a velocidade das intervenções na dinâmica da natureza, ocasionam transformações expressivas na paisagem, decorrentes da criação de novos equipamentos tecnológicos, que objetivam a exploração dos recursos naturais entendidos nesse processo como uma mercadoria.

Apoiado em Milton Santos (1997), Camargo (2008) considerou que a paisagem seria o resultado cumulativo dos tempos (transtempora), diferenciando-se de acordo com a dinâmica em que se insere cada região e, portanto, constituindo um subconjunto que, mesmo se apresentando como uma aparente totalidade é parte constituinte de um todo maior ou de uma dinâmica sistêmica maior.

\subsection{EXEMPLOS DAS TIPOLOGIAS E VULNERABILIDADES DA PAISAGEM}

No presente artigo a paisagem é concebida como resultado das inter-relações, conexões e transformações entre sociedade e natureza, no qual tem origem a partir das formas e cenários, que se compõem no passado e presente, em tempos longos e curtos.

A relação sociedade/natureza se estabelece da situação de ambiguidade procedentes da relação dialética, que é afirmada, pois a sociedade ao mesmo tempo em que é parte da natureza, se afirma como principal transformador devido à capacidade de trabalho, exploração e organização social.

Desse modo, apresenta-se como exemplo a Bacia Hidrográfica do Rio Salobra, localizada na região sudoeste do Estado de Mato Grosso do Sul, pode ser considerada uma das poucas regiões do Mato Grosso do Sul onde ainda é possível visualizar áreas que apresentam características naturais marcantes do ponto de vista das paisagens preservadas.

Destaca-se que a Bacia Hidrográfica do Rio Salobra é considerada uma das principais áreas fontes de fluxos de matéria e energia para Bacia do Rio Miranda no Pantanal Sul-mato-grossense. 
Segundo Silva Neto e Nunes (2011), verifica-se na área abordada uma configuração de paisagens vulneráveis, na qual alguns tipos de usos da terra podem desencadear os processos de degradação dessa paisagem. Uma porção significativa da Bacia Hidrográfica do Rio Salobra é caracterizada como um ambiente vulnerável de acordo com suas características físico-ambientais

Observa-se nos ambientes que apresentam relevo muito dissecado, solos rasos, onde não são desenvolvidas atividades agropecuárias e as áreas de floresta não foram substituídas por pastagem, apresentando ainda cobertura vegetal densa. Essas áreas apresentam expressivas características de paisagens naturais (Figura 3).
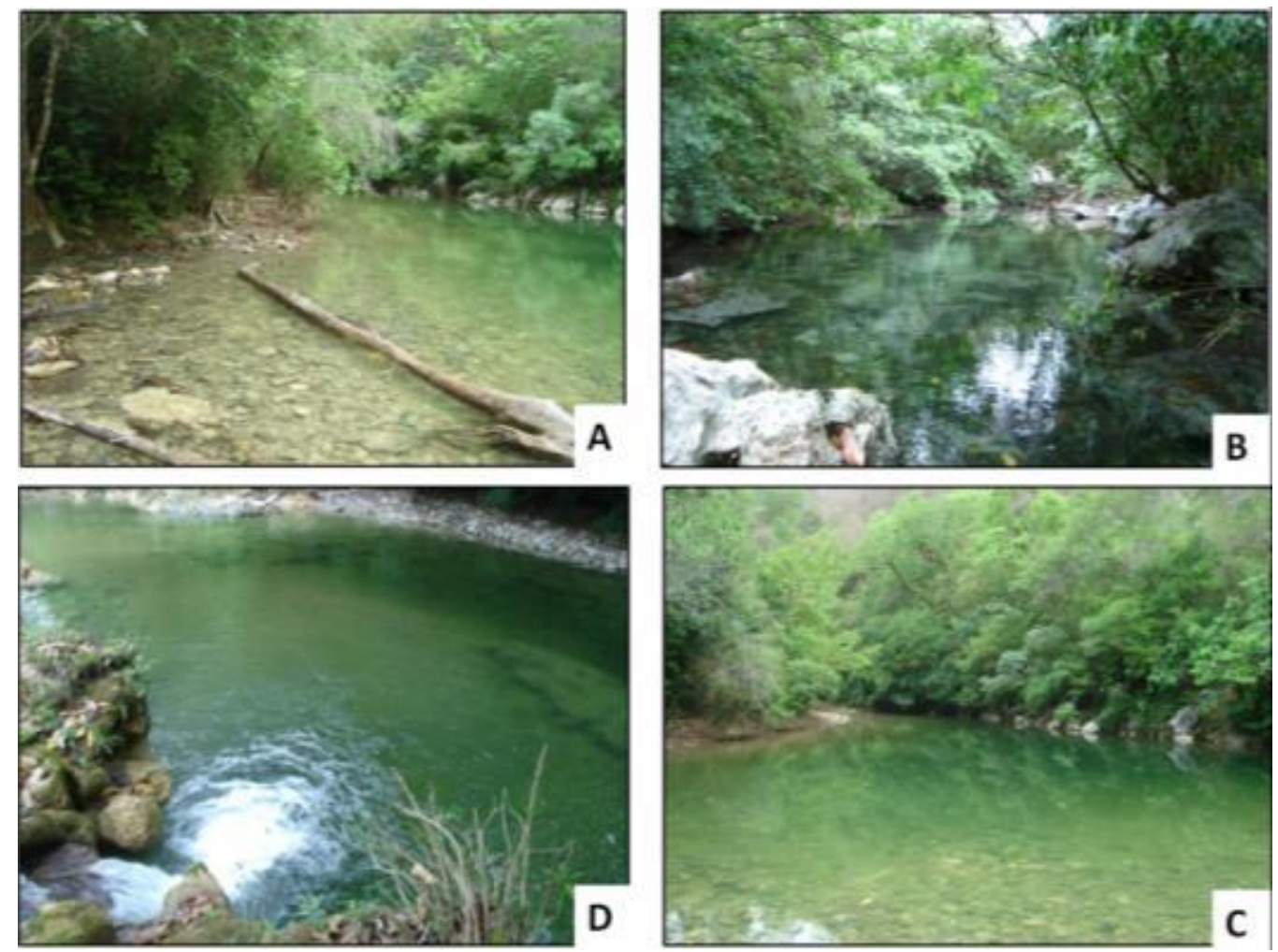

Figura 3- Paisagens ainda preservadas no alto curso do canal principal da Bacia do Rio Salobra, dentro do Parque Nacional da Serra da Bodoquena.

Observa-se o canal principal do Rio Salobra (Figura 4- A,B,C), no assentamento Canaã onde são desenvolvidas atividades como turismo, visualizando-se a cachoeira (Figura 4- D) utilizada como atrativo turístico. 

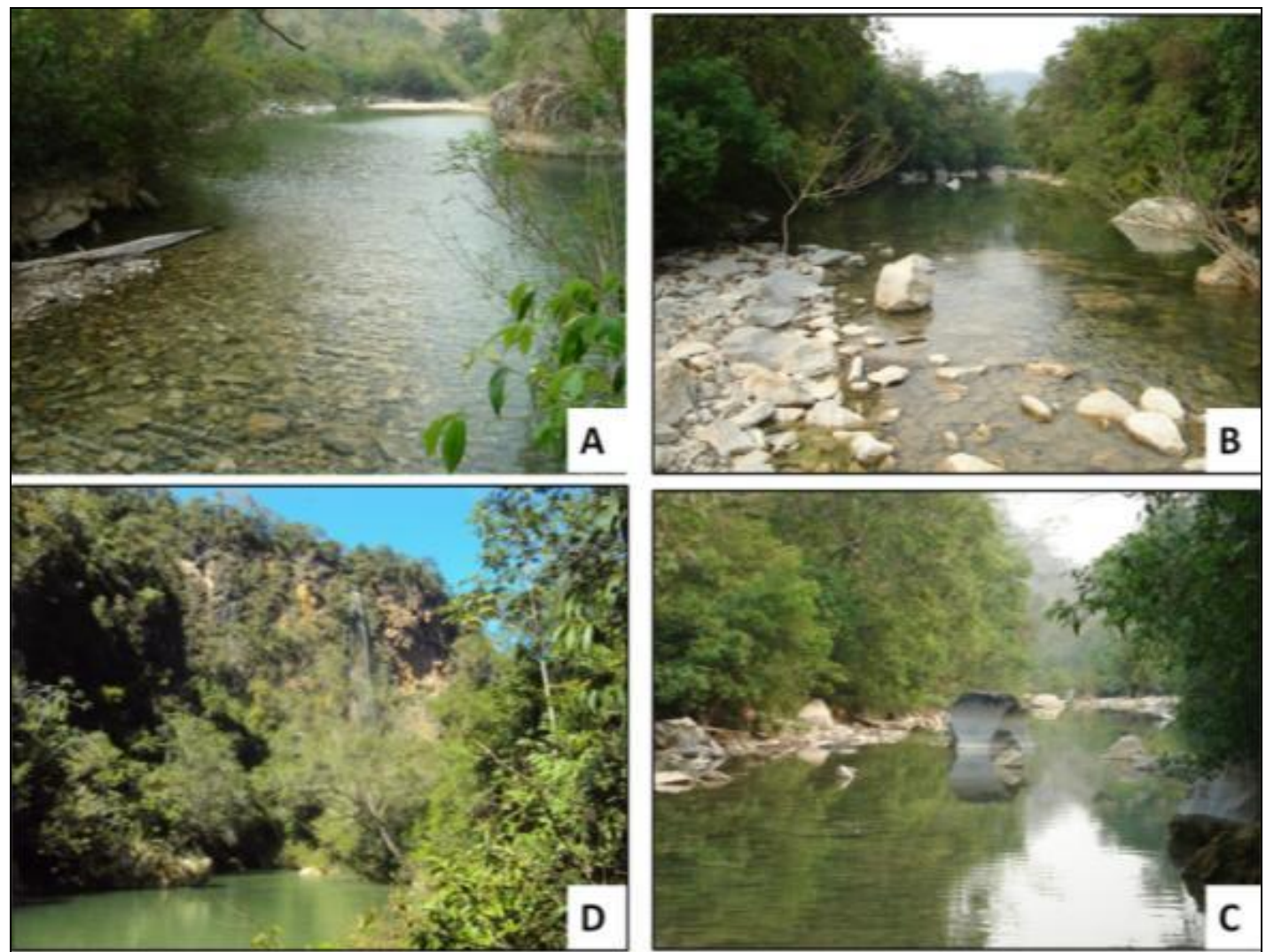

Figura 4- Paisagens da bacia hidrográfica do rio Salobra, no assentamento Canaã.

Nas paisagens de ambientes cársticos, característicos de rochas de carbonato de cálcio se visualizam cenários frágeis como grutas com drenagens subterrâneas (Figura 5 A, B), cavernas e suas feições com estalactites (Figura 5- C, D) e por último as cerâmicas indígenas descobertas dentro de uma caverna durante um trabalho de campo (E). Esses tipos de ambientes apresentam um significado histórico e cultural muito importante na construção dessas paisagens, no qual são destacados os primeiros indícios de ocupação da área por indígenas. 


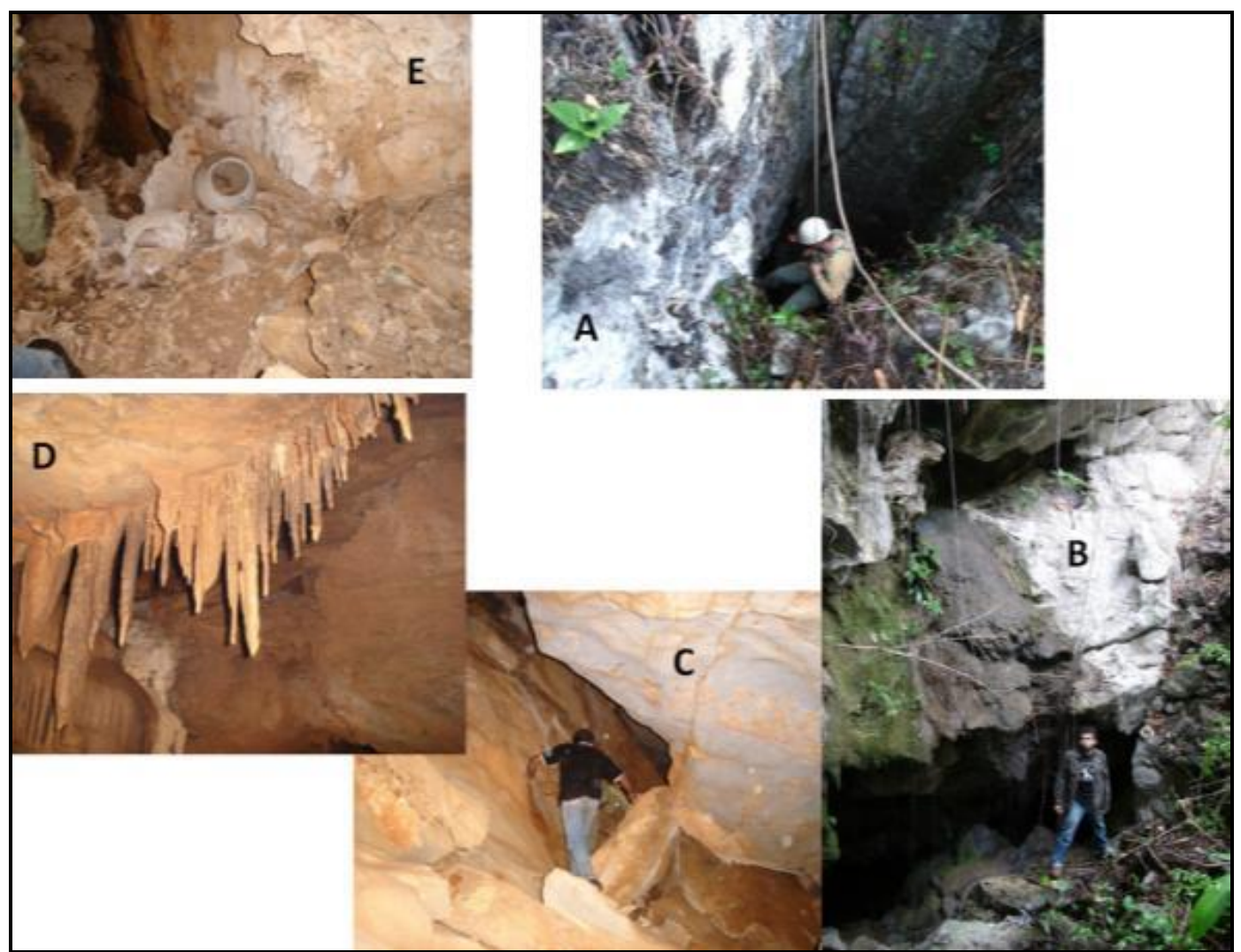

Figura 5- Paisagens de ambientes cársticos na Bacia Hidrográfica do Rio Salobra, no assentamento Campina.

As paisagens com expressivas alterações provocadas pela atuação antrópica, são definidas como paisagens homogêneas e heterogêneas, caracterizadas por apresentar pouca diversificação no tocante das espécies vegetais e animais, resultantes das alterações do ambiente natural e organizado por grupos humanos objetivando a produção econômica e social.

As paisagens antrópicas caracterizam-se pela junção dos elementos naturais com os elementos antrópicos dispostos de modo dialético, no qual, a relação simbiótica sociedade-natureza influenciará uma sobre a outra.

Desse modo, define-se por paisagem antrópica, o sistema natural produtivo composto por segmentos da natureza levemente a fortemente modificado adicionados aos sistemas tecnogênicos (antrópicos) (MILKOV, 1973 apud MATEO et al. (2007).

A visualização das atividades econômicas (Figura 6 - B) desenvolvidas na área, como a pecuária extensiva (Figura 6 -D e A) e a extração de calcário para indústria, 
provocam alterações ao ambiente natural resultando em uma nova configuração da paisagem (C), que se caracteriza principalmente pela perda dos seus atributos naturais.
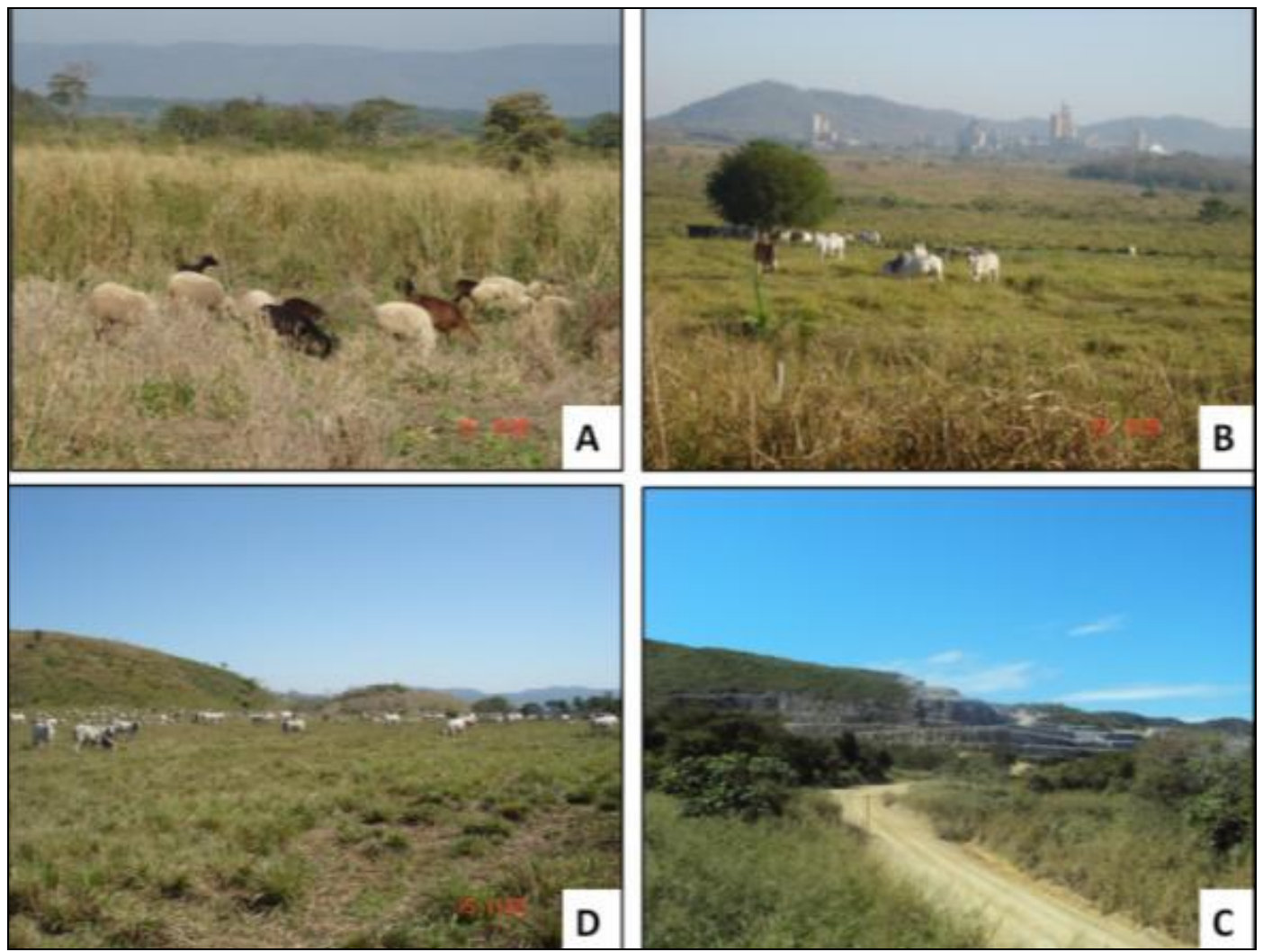

Figura 6- Paisagens antrópicas da Bacia Hidrográfica do Rio Salobra

$\mathrm{Na}$ Bacia do Rio Salobra são identificadas áreas com pequenas lavouras de subsistência, onde são produzidas culturas diversificadas como banana, cana de açúcar e feijão, em áreas de relevo plano ou suave ondulado (Figura 7- B), verifica-se também cenários com significativas áreas de lavouras de feijão e arroz (C), porém, a atividade econômica mais representativa na bacia é a pecuária extensiva, que exige maiores extensões de áreas para serem exploradas (D, A). 


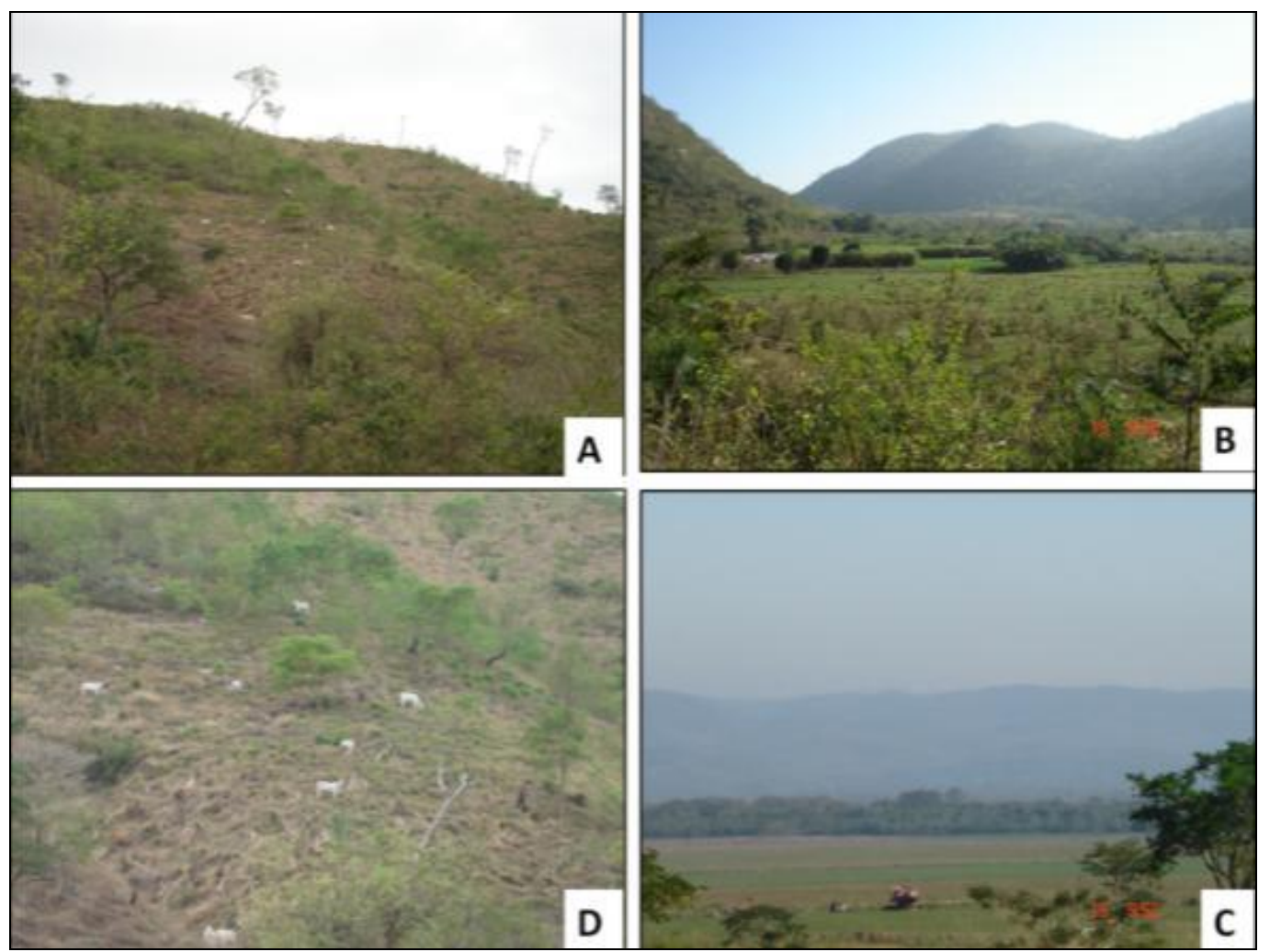

Figura 7- Paisagens antrópicas da Bacia Hidrográfica do Rio Salobra.

Essas paisagens se configuram na maioria das vezes como ambientes fortemente instáveis, que se caracterizam por seus altos níveis de alteração e transformação, que podem ocasionar degradação das áreas quando apresentar condições ecológicas difíceis de absorver esse tipo de impacto.

As alterações no funcionamento e nos mecanismos das relações de autoregulação conduzem a um processo de degradação, assim a auto-regulação dá lugar ao desequilíbrio na dinâmica funcional, resultando na dinâmica funcional degradante (MATEO et al. 2007).

As paisagens instáveis podem ser definidas pela perda de atributos e propriedades que possibilitam o cumprimento das funções e dos movimentos de autoregulação. Nesta direção, a instabilidade tem um papel significativo vinculado ao funcionamento do ambiente, pois conduzem à alteração dos mecanismos de autoregulação, da circulação de fluxo de Energia, Matéria e Informação e, por conseguinte, à perda dos potenciais naturais. 
Esses tipos de paisagens ocorrem, sobretudo, em áreas vulneráveis que apresentam uso da terra incompatível com os atributos físico-naturais, por exemplo, na Bacia Hidrográfica do Rio Salobra, em que são verificadas áreas de desmatamento em vertentes acentuadas e solos muito suscetíveis (Figura 8 - B), estes condicionantes muitas vezes levam à degradação dessas paisagens, acelerando processos os erosivos (Figura 8-C,D,A).

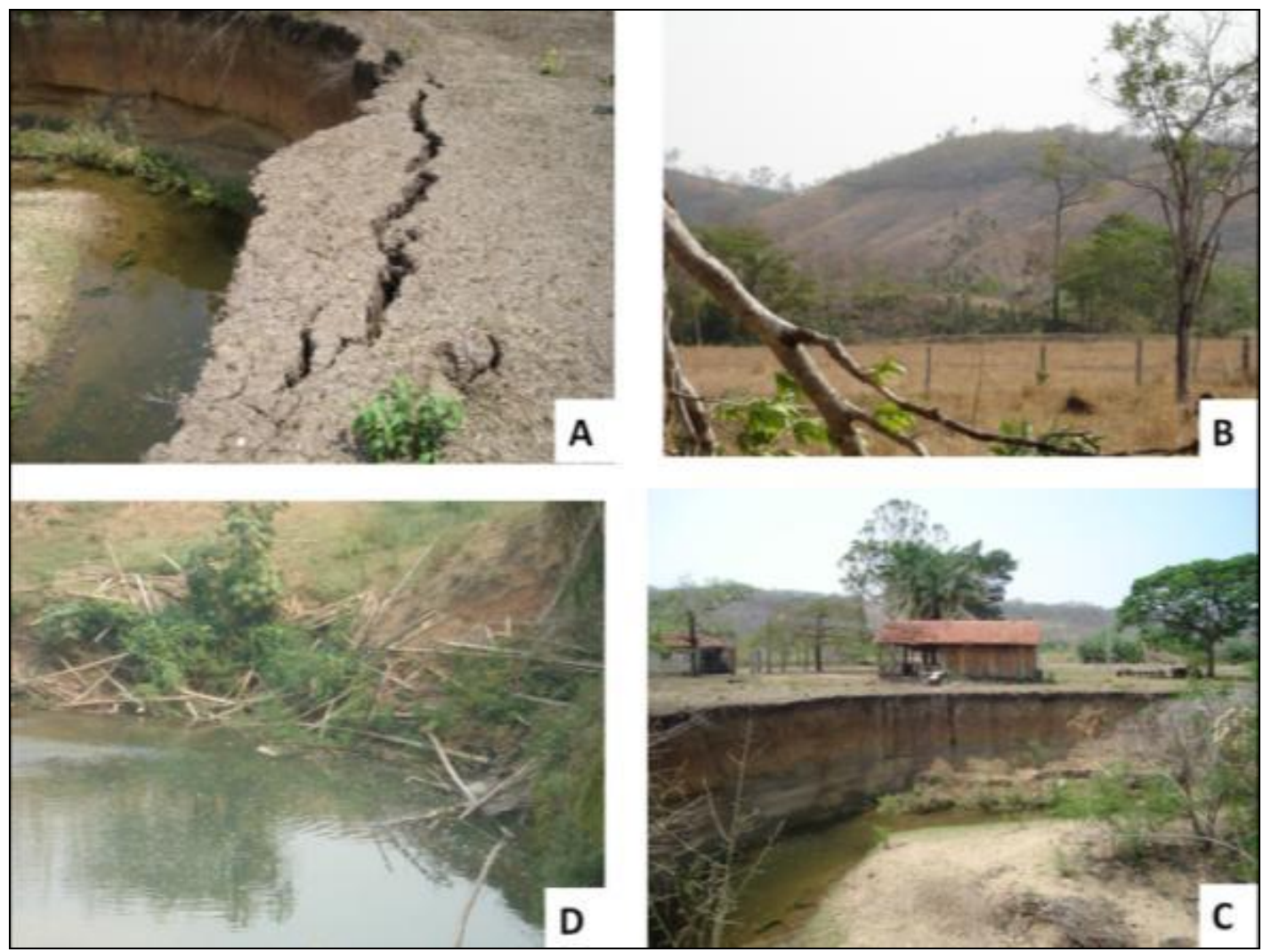

Figura 8- Paisagens antrópicas degradadas da Bacia Hidrográfica do Rio Salobra

Segundo Mateo et al. (2007) qualquer paisagem modificada ou transformada pelo homem, como regra, é menos estável que a paisagem original, pois o mecanismo natural de auto-regulação é alterado.

Entende-se auto-regulação estável as relações harmônicas com o meio externo e de um balanço de fluxos de EMI que garanta condições geoecológicas favoráveis ao impacto humano e de um processo de modificação e transformação antropogênica, sustentável e ambiental racional (MATEO et al. 2007). 
Trata-se de não ultrapassar um determinado nível de auto-regulação, assim a paisagem conserva a capacidade de auto-renovação, e a capacidade de renovar por si só, recuperando em pouco tempo o estado anterior à intervenção humana.

Nesse sentido definimos estabilidade como:

“... la facultad de conservar una situación de equilibrio al interior de la estructura de un paisaje cuando se encuentra sometido a influencias exteriores; esto implica procesos que permiten restablecer situaciones de equilibrio.

Para cualquier sistema físico se define como el hecho de volver a su estado anterior, después de haber sufrido los efectos de un impacto o perturbación de origen externo". (BOLÓS ${ }^{4}, 1987$, p.18).

A partir dos níveis da intensidade das ações antrópicas diferencia-se a paisagem como homogênea ou uniforme, considerando-se essas paisagens heterogêneas até sofrer um processo intenso de antropização resultando na homogeneização e uniformização da paisagem.

Um exemplo claro são as paisagens relativamente naturais, que apresentam altos níveis de diversidade biótica e abiótica, até o momento que ocorrem as alterações de cunho antrópico transformando ambientes complexos, como grandes áreas de florestas, em ambientes homogêneos e uniformes, como áreas agrícolas de monoculturas e de pastagens.

As paisagens antrópicas apresentam estados variáveis das condições naturais primitivas, revelando na sua dinâmica, as alterações decorrentes das relações sociedade e natureza, definindo-se como formação natural que passou por impactos sociais, econômicos e tecnogênicos (ROSS, 2006).

Moss (2000) ressalta que a apropriação da natureza tem exigido das paisagens agrícolas mais rapidez nos processos de transformações da natureza em mercadorias.

O processo de exploração das potencialidades naturais pode ser visualizado como um bom exemplo da degradação geoecológica, no qual o explorador, por meio de

\footnotetext{
${ }^{4}$ Tradução nossa: “... a capacidade de conservar uma situação de equilíbrio no interior da estrutura de uma paisagem quando ela se encontra submetido a influências externas, isto implica em processos que permitem restabelecer situações de equilíbrio.Para qualquer sistema físico se define como o fato de voltar ao estado anterior, depois de ter sofrido os efeitos de um impacto ou pertubação de origem externa."
} 
suas atividades transformando as potencialidades naturais em recursos, impõe uma nova dinâmica funcional, as paisagens exploradas e consequentemente o processo de funcionamento é condicionado a uma nova dinâmica funcional da paisagem.

O processo de apropriação social da natureza, por meio da exploração das potencialidades naturais impõe ao ambiente a intensificação do seu estado de entropia, uma vez que nesse ambiente são introduzidos vários elementos até então alheios aquela paisagem. Durante esse processo ocorre a degradação geoecológica e perda de atributos importantes para a produção, reprodução e funcionamento da paisagem.

Para Mateo et al. (2007) os processos degradantes são consequência da pressão sobre os sistemas naturais, constituindo-se um produto direto resultante da ação antrópica, entendido como problemas ambientais por desarticular a estrutura de funcionamento dos sistemas naturais, resultando na dificuldade do cumprimento das funções socioeconômicas das paisagens.

Silva Neto (2013) analisando as diferentes paisagens da Bacia Hidrográfica do Rio Salobra numa perspectiva temporal comparou uma determinada realidade de uma paisagem pretérita (ano de 1979), que provavelmente já tenha sido transformada, com uma realidade recente, em que configuram-se as paisagens atuais (ano de 2009) (Gráfico 1).

Gráfico 1- Vulnerabilidade das paisagens à perda de solos na Bacia Hidrográfica do Rio Salobra nos anos de 1979 e 2009.

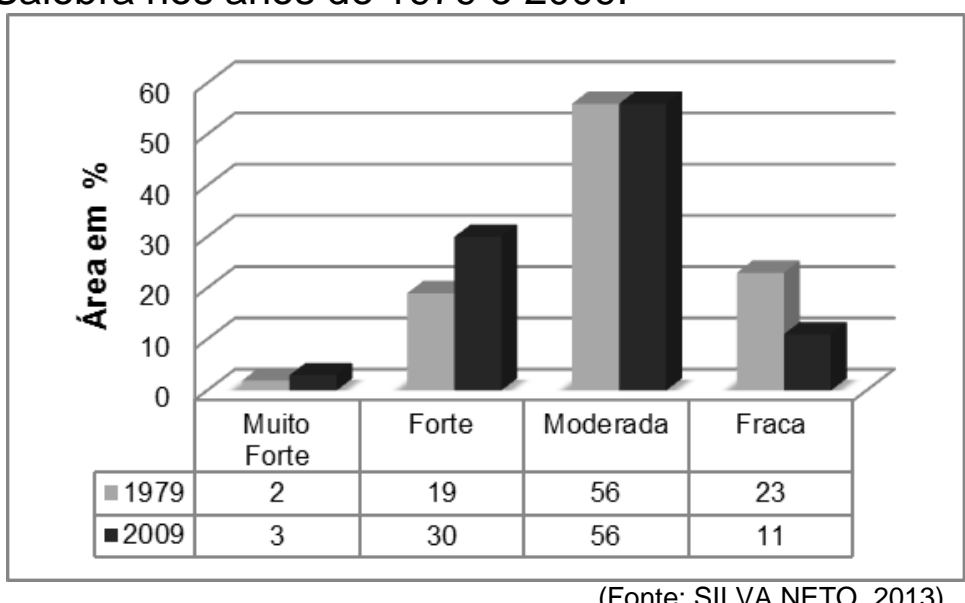

(Fonte: SILVA NETO, 2013). 
Observou-se que nas últimas décadas o nível de vulnerabilidade da paisagem na Bacia Hidrográfica do Rio Salobra, aumentou devido aos processos antrópicos impulsionados principalmente pelas intencionalidades intrínsecas em cada tipo de uso da terra, na qual áreas que anteriormente apresentavam baixo nível de vulnerabilidade foram alteradas para altos níveis de vulnerabilidade em decorrência expansão de tipos de uso da terra como a pecuária extensiva.

Portanto, é extremamente necessária a formulação de medidas mitigadores e do zoneamento ambiental dessa área, contribuindo para regularização/restrição de algumas formas de uso da terra, no intuito de preservar as características naturais desse importante ambiente tropical.

\section{3 - CONCLUSÃO}

De acordo com a discussão apresentada no presente texto, pode-se considerar que a vulnerabilidade da paisagem pode ser entendida como a capacidade maior ou menor, de um sistema em transitar do estágio de estabilidade para um estágio de instabilidade, indicando assim, o grau de alteração que a paisagem experimentaria diante das incidências de determinadas atuações, resultando nas diferentes tipologias da paisagem.

Enfatiza-se ainda que os níveis de vulnerabilidade na paisagem se estabelecem a partir da relação direta da intensidade de atuação antrópica resultando em diferentes tipologias da paisagem.

Ressalta-se que as intencionalidades sociais que movem as ações humanas sobre a natureza são impulsionadas por uma racionalidade econômica que visa tornar qualquer área explorável, não se respeitando os limites físico-naturais de cada área.

O processo de apropriação social da natureza, por meio da exploração das potencialidades naturais impõe ao ambiente a intensificação do seu estado de entropia e instabilidade, uma vez que nesse ambiente são introduzidos vários elementos até então 
alheios àquela paisagem. Durante esse processo pode ocorrer a degradação geoecológica e perda de atributos importantes para o funcionamento da paisagem.

Compreende-se ainda, que os estudos da paisagem e o entendimento de sua estrutura e dinâmica possibilitam subsidiar e direcionar as ações humanas, no qual a relação da estrutura natural da paisagem com as diversidades de uso associadas aos diferentes tipos e graus de utilização, são procedimentos elementares na análise da paisagem e, esta análise deve resultar em estimativas que devem relacionar-se com a análise funcional e a evolutiva da paisagem.

Assim, conclui-se que as condições mais ajustadas do ordenamento espacial da paisagem resultam da procura de proporção adequada das áreas, para os tipos e intensidade de usos, que dependem das características da estrutura e dos indicadores da paisagem.

\section{REFERÊNCIAS:}

CAMARGO, Luís Henrique Ramos de. A ruptura do meio ambiente: conhecendo as mudanças ambientais do planeta através de uma nova concepção da ciência: a geografia da complexidade. 2a Ed. - Rio de Janeiro: Bertrand Brasil, 2008.

CREPANI, Edison et al. Zoneamento Ecológico-econômico; In: FLORENZANO, Teresa G; Geomorfologia: Conceitos e tecnologias atuais. São Paulo, Oficina de Textos, 2008.

MATEO, José Manuel; et al. Geoecologia das Paisagens: uma visão geossistêmica da análise ambiental. 2ª Ed. Fortaleza: Edições UFC, 2007.

MELO, Rosangela Maria de, et al. Utilização de Análise Multicriterial na elaboração de mapas de vulnerabilidade do estuário do Rio Formoso/PE; In: Anais XV Simpósio Brasileiro de Sensoriamento Remoto - SBSR, Curitiba, PR, Brasil, INPE; p.6026-6033, 2011.

MENDONÇA, Francisco de Assis, Geografia e meio Ambiente; $3^{\text {a }}$ Ed. São Paulo: Editora Contexto, 1998.

MOSS, Michael R., Interdisciplinarity, landscape ecology and the 'Transformation of Agricultural Landscapes'; In: Landscape Ecology. Kluwer Academic Publishers. Printed in the Netherlands. n. 15, p. 303-311, 2000. 


\section{Then Fórum Ambiental \\ da Alta Paulista

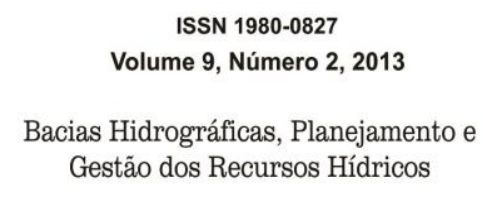 \\ Gestão dos Recursos Hídricos}

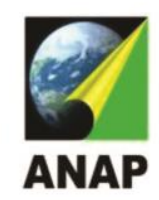

NÁPOLES, Carmen Sara; Un acercamiento al tema de la vulnerabilidade social; In: LEMOS, Amália Inês G., ROSS, Jurandir L. Sanches,LUCHIARI, Ailton (org.), América Latina: sociedade e meio ambiente. 1aㅡ. Ed. São Paulo: Expressão Popular (Série Por uma geografia Latino-americana. p.139-156, 2008.

ROSS, Jurandir Luciano Sanches. Ecogeografia do Brasil: Subsídios para planejamento ambiental. São Paulo: Oficina de Textos, 2006.

SANTOS, M. A natureza do espaço: técnica e tempo, razão e emoção. 2. ed. São Paulo: Hucitec. 1997.

SILVA NETO, J. C. A. Zoneamento ambiental como subsídio para o ordenamento do território da bacia hidrográfica do rio Salobra, Serra da Bodoquena - MS. Tese (Doutorado em Geografia) - Programa de Pós-Graduação em Geografia da Universidade Estadual Paulista, Presidente Prudente. Fevereiro de 2013.

SILVA NETO, J. C. A \& NUNES, J. O. R. Vulnerabilidade da paisagem à perda de solos na Bacia Hidrográfica do Rio Salobra-MS. In: Anais do IX Encontro Nacional da Associação de Pós-graduação em Geografia ENANPEGE, Goiânia - GO, 2011.

SUERTEGARAY, D. M; NUNES, J. O. R. A natureza da Geografia Física. Revista Terra Livre, São Paulo, v. 1, n. 16, p.11-24, 2001.

SUERTEGARAY, Dirce M. A. Espaço Geográfico Uno e Múltiplo, In: Scripta Nova, Revista Electrónica de Geografía y Ciencias Sociales. Universidad de Barcelona n 93, 2001.

VITTE, Antonio Carlos, O Desenvolvimento do Conceito de Paisagem e a sua inserção na Geografia Física, Mercator - Revista de Geografia da UFC, ano 06, número 11, p. 71-78, 2007.

TAGLIANI, Carlos Roney Armanini, Técnica para avaliação da vulnerabilidade ambiental de ambientes costeiros utilizando um Sistema Geográfico de Informações; In: Anais XI Simpósio Brasileiro de Sensoriamento Remoto - SBSR. Belo Horizonte, Brasil, INPE, p. $1657-1664,2003$. 